\title{
El razonamiento jurídico
}

Rubén M. Garate ${ }^{1}$

Resumen: El razonamiento jurídico, es una estructura de pensamiento que no solo incluye elementos de la lógica formal, sino también de la lógica dialéctica, lo que nos permite vislumbrar la necesidad de un análisis desde la Filosofía del Derecho como de la Teoría General del Derecho. Este tipo de razonamiento pretende alcanzar cierto grado de verosimilitud, al fundarse en argumentos retóricos que lo constituyen y estructuran. El proceso argumentativo es encuentra intimamente relacionado con la interpretación normativa, porque se necesita comprender acabadamente el derecho, para luego encontrar criterios que fundamenten el razonamiento jurídico. Sobre la interpretación que realicen los tribunales inferiores por medio de sus resoluciones, es posible realizar el control de logicidad, con la finalidad de otorgarle el máximo grado de corrección a este tipo de razonamiento.

Abstract: Legal reasoning is a structure of thought that, not only includes components of formal logic but also of dialectical logic, allowing us to discern the need of an analysis from the Philosophy of Law and also from the General Theory of Law.

This kind of reasoning expects to achieve a certain degree of plausibility, being based on rhetorical arguments that constitute and structure it.

The argumentative process is closely related to the normative interpretation, because it is necessary to fully understand the Law to be able to find criteria that support legal reasoning.

About the interpretation made by an inferior court according to its resolutions, it is possible to exercise control of Logic with the aim of granting the highest degree of correction to this kind of reasoning.

\section{Introducción}

El razonamiento jurídico pretende como fin último la búsqueda de una solución ante el conflicto, por medio de la aplicación de una proposición normativa, que debe ser justificada y fundada como fruto de una decisión.

\footnotetext{
${ }^{1}$ Garate Ruben Marcelo, Abogado, Profesor en Filosofía y Ciencias de la Educación. Docente de la Facultad de Ciencias Jurídicas y Sociales de la UNLP. www.garate@jursoc.unlp.edu.ar
} 
Explorar la razón jurídica implica traspasar el campo de la lógica tradicional, en busca de la razón vital e histórica o mejor dicho establecer una lógica de la acción, ya que la vida humana es el reino de la acción y la libertad.

La norma jurídica se presenta de este modo como una porción de vida humana objetivizada, encarnando un tipo de acción, convirtiéndose en pauta normativa dentro de un proyecto jurídico. Sin embargo ella debe ser adaptada por los órganos jurisdiccionales, que establecen su singular aplicación. Este proceso de individualización y concreción nos muestra el sentido dinámico de las normas jurídicas, que requieren de la utilización de una lógica de la acción humana referida a valores y encaminada a la realización de fines. Esto es lo que Recacéns Siches (1956) llama lógica de lo razonable, porque deberá tenerse en cuanta a) las normas jurídicas, b) desde u punto de vista histórico, y c) según un aspecto práctico o de aplicación del orden jurídico vigente.

El campo de la razón jurídica, es un ámbito diferente que llamaremos lo razonable, a la que denominamos de este modo porque produce juicios de valor al enunciar argumentos estimativos. Sin que por ello renunciemos a la lógica formal aristotélica, como base para la estructura de todo razonamiento.

Debemos tener en cuenta que Teodor Viehweg afirma que el dominio de lo racional es más extenso que el de la lógica formal (Pettoruti. 2004). No hay dos tipos de lógicas, antagónicas entre sí; sino que existe una lógica formal y una lógica dialéctica que incorpora además, aspectos de la lógica material. Sobre esta base estructura la tópica, entendida como una técnica de la retórica, nos posibilita obtener fundamentos para la argumentación, orientando al pensamiento hacia aquellos lugares comunes que se presentan como problemas (Pettoruti-Scatolini. 2005).

Para Aristóteles la tópica es un capítulo específico de la lógica dialéctica, imprescindible para la argumentación discursiva, al permitir establecer las premisas, sobre las cuales se asienta un discurso que pretende ganar el asentimiento del auditorio.

La jurisprudencia necesita del método tópico, porque le otorga una técnica intelectual que por medio de la retórica, le permite obtener instrumentos que posibiliten la argumentación, con la finalidad de sacar conclusiones con relación a algún problema. Para utilizar el razonamiento dialéctico, es necesario tomar como punto de partida premisas verosímiles, que si bien, no llegan a ser estrictamente verdaderas, pueden ser 


\section{Derecho y Ciencias Sociales, Abril 2009, Nº1. Pgs.194-215. ISSN 1852-2971}

Instituto de Cultura Jurídica y Maestría en Sociología Jurídica. FCJyS, UNLP

tenidas como probables, siendo acreditadas por una general aceptación (Diez Picaso. 1994).

La importancia que tiene la dialéctica, para el mundo jurídico, la podemos descubrir con solo pensar, en el derecho procesal que tiene por fin regular la forma de la disputa o controversia judicial, en el que las partes se lanzan en una discusión argumentando y rebatiendo, esperando que un tercero imparcial de crédito a sus posturas y falle según lo dicte el derecho (Ghirardi. 1987).

El presente trabajo pretende indagar en los aspectos más importantes de la lógica de lo razonable, en el cual la argumentación juega un papel fundamental y mientras que la interpretación jurídica como proceso herméneutico, no se encuentra ajena

\section{Lógica de lo razonable}

Siguiendo nuestra reflexión podemos decir, que mientras la lógica formal nos enseña las reglas del razonamiento para alcanzar la corrección. Descubrimos que esta misma corrección se nos presenta como fin inmediato del razonamiento (Ghirardi. 2005). A todo razonamiento, le atribuimos un carácter instrumental porque nos permite conquistar distintos grados de certeza, que podemos clasificar como autoevidente (demostrable, plausible y aparente). En este sentido, la lógica formal como la lógica dialéctica, deben integrarse y complementarse frente a las necesidades del discurso jurídico, para que sea aceptado como razonable, siempre que se encuentre sujeto a determinado criterios de corrección ya que debe establecer consideraciones sobre lo "justo".

Para la filosofía general, las tres operaciones del espíritu son, la aprehensión, el juicio y el razonamiento. Que nos permiten producir conceptos, que serán expresados por palabras o, unir o dividir conceptos y por último, como más elevada operación encontramos al razonamiento, que nos posibilita agrupar proposiciones buscando dar complejidad a nuestro pensamiento y de este modo fundamentar, nuestra acción o modo de pensar por medio de la argumentación, como justificación de nuestro actuar, y sobre los que predicamos la verdad o verosimilitud de los mismos (Maritain. 1980).

Los estudios de Armando Andruet (2000. p 27), sobre la lógica no formal, nos hablan del olvido de la lógica dialéctica por parte de la filosofía moderna. Proceso que se inicia con Descartes y es acompañado por Locke. Fundamentando tal actitud en la necesidad de una "razón" de tipo demostrativa, según las necesidades del espíritu 
moderno, para el cual solo hace falta una lógica formal que otorgue carácter científico a sus conclusiones. Despreciando de este modo la lógica dialéctica, al pensar que ella era una manipulación de los sentimientos, basada en construcciones artificiales y figuradas, portadora de un aspecto totalmente subjetivo.

\section{La nueva lógica jurídica}

Si de lógica hablamos no podemos dejar de hacer referencia a uno de los jusfilósofos más importantes del siglo XX como Chain Perelman, que no solo a demostrado la importancia de la dialéctica, sino que además comprendió la necesidad de un nuevo campo de investigación en la filosofía del derecho como el de la lógica jurídica, propia y distintiva del mundo normativo (Perelman 1979).

Partiendo de una premisa fáctica, cuando afirmamos que el razonamiento, es la actividad mental. Así, la elaboración de una conclusión o solución, implica la necesidad de reconocer, la validez de ciertas reglas lógicas, que serán necesarias a la hora de producir el razonamiento. Por ello el entinema o silogismo dialéctico, se funda en lo verosímil o plausible, porque se necesita de buenas razones que justifiquen nuestras decisiones.

Sabemos de la importancia de la lógica formal y su naturaleza analítica. La que permite que el método científico logre estructuración y sistematicidad en función del razonamiento explicativo, utilizado por el método inductivo. Ella permitirá asegurar que la demostración racional, es una construcción ordenada (Millan Puelles. 1981).

La importancia de la obra de Perelman (1979) está en recuperar esta disciplina de la tradición aristotélica, sacándola del terreno meramente técnico o instrumental a la que había sido llevada por los escolásticos y luego por los modernos, para reintroducirla en la arena propiamente científica ${ }^{2}$. Su teoría de la argumentación, utiliza la razón práctica con la intención de influir no solo en el comportamiento de los demás, sino también en el auditorio procurando producir la "adhesión" en los espíritus. La retórica se desarrolla en función del auditorio y como técnica de motivación e incentivación.

\footnotetext{
${ }^{2}$ Actualmente existen distintas escuelas en el terreno de la "teoría de la argumentación". Una de ellas es la escuela francesa de Ducrot-Anscombe (1982). Su perspectiva es netamente lingüística y no tiene mayores puntos de contacto con la teoría de la argumentación de Perelman. Basada en el concepto de "polifonía" incorpora el análisis de las múltiples perspectivas de "enunciadores" en el análisis del acto de la enunciación. Aunque esta concepción puede resultar igualmente útil para el análisis de la experiencia medida por normas, no la consideraremos dado que no se interesa, de manera franca, como lo hace la de Perelman, por la problemática práctico-jurídica subyacente a la argumentación
} 


\section{Derecho y Ciencias Sociales, Abril 2009, Nº1. Pgs.194-215. ISSN 1852-2971}

Instituto de Cultura Jurídica y Maestría en Sociología Jurídica. FCJyS, UNLP

Efectivamente, la argumentación está destinada a valorar los hechos conforme a un principio o norma, reconocido como válido y a decidir o fundamentar la acción que de dicha valoración se sigue. Para Perelman (1979) la dialéctica o la retórica se ocupa de las opiniones, siendo ellas las que nos pueden conducir tanto al saber verdadero como también al error. Es que en el terreno de lo opinable, no encontramos evidencias, sino solo variedad de posturas y apariencias de la realidad que nos impide verla tal cual es, poniéndose en juego las impresiones subjetivas por encima de la objetividad (Recaséns Siches. 1971). Mientras que la verdad no depende del tiempo ni de los caracteres individuales del espíritu. No tiene que ver con ningún factor situacional, ni con una creación individual o social.

\section{Lógica dialéctica e interpretación jurídica}

Perelman distingue tres momentos diferentes en la evolución de la lógica jurídica en función de las distintas etapas interpretativas (Perelman 1979).

El último de los tres períodos evolutivos, está signado por la búsqueda de una solución equitativa y razonable, manteniéndose dentro de los límites que el sistema jurídico le impone. Aquí debemos considerar a la concepción interpretativa del voluntarismo estructurado ${ }^{3}$, quien afirma que el juez no se nueve en el vacío, al aplicar normas generales, produciendo de este modo un acto de creación, como presupuesto de su decisión; la interpretación es el fruto de la estimativa jurídica.

En la visión escalonada del sistema jurídico propuesta por Hans Kelsen, nos permite observar que existen normas jurídicas que habilitan la producción de otras normas, estableciéndose una gradación de normas. Así es posible determinar que en este sistema escalonado la producción del derecho es un proceso sucesivo en el que no solo se ejecuta derecho, sino que también se crea el derecho, de tal modo que los actos jurídicos tienen una función ejecutiva del derecho y una función creadora del derecho (Walter. 2001).

En este sentido Kelsen sostiene que la norma superior establece el acto de creación de la inferior, pero de modo parcial en relación a su contenido; al presentarse como una especie de marco que es necesario llenar.

\footnotetext{
${ }^{3}$ Si bien también es posible distinguir otra corriente, la del voluntarismo amorfo desarrollada por la escuela del derecho libre, sostiene que todo queda librado a la voluntad decisoria del juez (Cossio $E l$ derecho en el derecho judicial, pág, 132)
} 


\section{Derecho y Ciencias Sociales, Abril 2009, №1. Pgs.194-215. ISSN 1852-2971}

Instituto de Cultura Jurídica y Maestría en Sociología Jurídica. FCJyS, UNLP

Lo indeterminado puede ser tanto lo referido al hecho ilícito como a la sanción. Por eso el poder legislativo puede determinar el "género" normativo, como el caso de una epidemia sobre la que se prevé cierto modo de actuar, más no se determina la "especie" (gripe, fiebre amarilla, tifoidea). En la otra circunstancia, encontramos que si el Código Penal puede establecer mínimos y máximos de la pena, deja al juez la facultad de determinar la cuantía de la misma. En este caso la norma particular, se relaciona análogamente, con esta vinculación descripta de relación de género a especie.

La norma superior presenta un marco de posibilidades al intérprete, sin embargo cuando la vaguedad de la letra de la ley resulta un problema, no encontramos en la Teoría Pura una solución, por lo que podemos destacar que el positivismo kelseniano no presenta un método interpretativo (Kelsen. 1992) que determine claramente pautas de acción.

La interpretación sólo puede trazar racionalmente diferentes soluciones otorgando igual valor a cada una de ellas. Frente a esta ilusoria seguridad jurídica, Robert Walter (2001) entiende necesario recurrir a la conjunción de los más importantes métodos interpretativos (literal, histórico-psicológico, teleológico).

Dentro de la misma posición voluntarista la Teoría Egológica de Carlos Cossio (1940), introduce un nuevo enfoque al entender que la tarea interpretativa debe ser científica, para la cual necesita de un método específico según el objeto en análisis. El derecho dentro de la Teoría Egológica, es considerado un objeto cultural ${ }^{4}$, lo que nos lleva a descubrir un plano ontológico específico y propio de la Ciencia Jurídica sobre el que debe abocar su estudio, requiriéndose para tal empresa un método específico, que Cossio denomina empírico dieléctico.

Este método requiere que partamos de la experiencia, del caso particular dada por la conducta intersubjetiva, que se constituye en substrato objetivo. Mientras que la comprensión, como acto gnoseológico nos permite relacionar el substrato con su sentido, aproximándonos a una faz dialéctica del método, en la que el espíritu entabla un diálogo entre ambos elementos que nos permite descubrir cómo el substrato alberga un sentido (Machado Neto. 1974). Esta característica dialéctica es propia de la complejidad de los objetos culturales, que poseen una estructura por demás compleja.

\footnotetext{
${ }^{4} \mathrm{Si}$ bien Cossio distingue entre los objetos culturales los que poseen un substrato natural incorporan un sentido distinto del que poseía naturalmente, y que fuera otorgado por el hombre convirtiéndolo en objeto mundanal; por eso la piedra es transformada por el escultor en una obra de arte.
} 
No cabe duda para la teoría egológica, el juez debe lograr objetividad en su sentencia, la que solo es lograda si su fallo se encuentra en consonancia con el resto de la jurisprudencia, logrando de este modo un criterio intersubjetivo, propio de una experiencia jurídica estimativa ${ }^{5}$.

Este punto de vista gnoseológico intersubjetivo debe ser válido para todos los que se coloquen en el mismo lugar de conocimiento. En este acto debemos distinguir la norma como texto, de lo expresado por ella que llamamos significación ${ }^{6}$.

Según Husserl en todo acto de expresión encontramos un signo y una expresión, en definitiva un texto que nos dice algo sobre "algo"; motivo por el cual podemos distinguir que objeto y concepto no es lo mismo.

Esto lleva a la Teoría Egológica a distinguir en el acto interpretativo, un primer elemento compuesto por el texto normativo, que nos dice "lo expuesto", el que se convertirá objeto del análisis. Por otro lado, un segundo elemento consistente en "lo expresado" en el texto, es decir su significación, que llamamos norma en sentido propio - ya que Cossio no identifica el texto con la norma, sino con su significación. Como tercer componente encontramos a la conducta, como aquello sobre lo cual se dice "algo" y que posee para el derecho, siempre un carácter intersubjetivo. Este tercer elemento nos permite descubrir la importancia del cuarto elemento de la interpretación, la intuición sensible y axiológica, del que será objeto la conducta que está por conocerse.

Siguiendo en este tema a Juan Carlos Smith, diremos que la norma está en relación dialéctica con la conducta y que ambas se coimplican, en la medida que la norma nos permite comprender la conducta y a su vez la conducta interpretar la norma. No creemos estar distantes de Husserl ya que el mismo en sus "Investigaciones Lógicas", entiende que se debe partir del sentido de las palabras para descubrir su significación, para luego avanzar progresivamente hacia la realidad misma. En este sentido, la esfera de la conciencia y su constitución son resueltas por Husserl, al explicar que la existencia del mundo exterior al ser percibida por los sentidos, no es otra

\footnotetext{
${ }^{5}$ Cossio entiende que los sistemas interpretativos son derecho positivo ya que ellos establecen normas que determinan la conducta del juez (El substrato filosófico de los métodos interpretativos, $\mathrm{pg}$, 34).

${ }^{6}$ Para Dilthey la interpretación es parte del acto gnoseológico de comprender, por lo que solo puedo interpretar en la medida que he comprendido. Proceso que implica partir de la manifestación de los signos sensibles hacia su significación ( Paul Ricour Del texto a la acción. Buenos Aires. Fondo de Cultura Económica. 2001, pág, 132.
} 


\section{Derecho y Ciencias Sociales, Abril 2009, №1. Pgs.194-215. ISSN 1852-2971}

Instituto de Cultura Jurídica y Maestría en Sociología Jurídica. FCJyS, UNLP

cosa que un "dato"7, susceptible de ser significada intersubjetivamente, en relación, al intercambio de experiencias, que en su conjunto constituyen el mundo de la comprensión.

En esta discusión están en juego dos visiones gnoseológicas diferentes: A) la kantiana, que entiende el mundo exterior como información del material sensible a través de las categorías, que le otorgan a la conciencia una función trascendental constitutiva del mundo categorialmente. B) fenomenológica, que realiza en un primer momento una reducción eidética, que hace patente la esencia, y luego produciendo una reducción trascendental, en la cual el objeto y el conocimiento son en cierto modo "uno" (Stein.2003).

Sin embargo debemos destacar una doble función objetivante de la norma que transforma el acontecer físico por medio de la acción humana en parte del conocimiento jurídico, cuyas connotaciones resultan verificables desde un doble punto de vista: lógico y axiológico (Smith. 1990). Desde este aspecto, podemos observar que el lenguaje normativo determina un significado racionalmente inteligible de aquellas acciones que los individuos pueden realizar en ciertas circunstancias. Las que pueden ser consideradas lícitas o ilícitas; permitidas o prohibidas; productora de deberes o generadora de facultades.

Desde el punto de vista axiológico, las vivencias estimativas quedan representadas implícitamente en las referencias lingüísticas, al momento de calificarlas como buenas o malas, justas o injustas, útiles o inútiles, provechosas o perjudiciales, correctas o repudiables. Las acciones humanas reguladas resultan axiológicamente estimables como conformes o contrarias con las finalidades por el conocimiento y voluntad de la fuente normativa. De este modo, la norma jurídica y la conducta humana normada constituyen así el núcleo del conocimiento jurídico.

En igual sentido se expresa Aulius Aarnio (2003) al sostener que la ciencia jurídica debe presentar puntos de vista acerca de las normas jurídicas válidas. Al sostener la necesidad de la dogmática jurídica, que analice e interprete la proposición normativa, pero que a su vez sistematice este material utilizando ciertos criterios especiales, indispensables para enfrentar los "hard-cases" (casos difíciles) en los que el

\footnotetext{
${ }^{7}$ Siguiendo el planteo fenomenológico Cossio reconoce que "el dato" se constituye en el objeto de conocimiento, según la concepción categorial con que se aprehenda. $\mathrm{Y}$ entiende que esto es suficiente para reducir eideticamente el objeto del derecho a la conducta. Sin embargo nosotros entendemos que no es conducta pura; sino conducta categorizada normativamente; por lo que no podemos realizar tal reducción.
} 
texto ambiguo de la ley produce al menos dos interpretaciones semánticas diferentes y legalmente posibles entre las que el juez debe optar para dar fin a la divergencia y expedirse.

La certeza jurídica, solo se logra cuando una decisión no es arbitraria, esto implica que ella mantiene una relación intima con un precedente y por lo tanto podemos decir que es predecible. La otra característica que debe tener la decisión, es que se debe considerar como adecuada, porque no solo la decisión debe estar de acuerdo con normas jurídicas sino que también deben respetar ciertos criterios axiológicos y morales. En este sentido Aarnio (2003) plantea la necesidad de que la decisión judicial sea axiológicamente válida, para que ella sea aceptable no solo en un sentido formal (válida y efectiva), sino también en un sentido material. Llegando a reconocer que la aceptabilidad social legitima la decisión. La que solo es posible alcanzar por medio del discurso racional $^{8}$ que utiliza un procedimiento de justificación, fundado en argumentos jurídicos, empíricos y morales, según el sistema de valores aceptados mayoritariamente por la sociedad.

No podemos dejar de coincidir con las ideas de Smith (1990) cuando afirma, que la interpretación jurídica se revela como un movimiento de síntesis, que comienza con una tarea de clarificación del lenguaje normativo y finaliza con la búsqueda de la corrección del sentido jurídico de la decisión judicial que adquiere al valorarse el comportamiento humano en virtud de la aplicación potencial o actual de la norma que es objeto de interpretación.

Pensar en un movimiento de síntesis, implica una postura de integración que no es arbitrario u ocasional, sino lógicamente necesario en función de realizar una dilucidación semántica de la norma, con motivo de conocer y juzgar sobre un hecho concreto que es nada más, ni nada menos, para las partes que lo sufren un dramático conflicto de intereses.

Por esto resulta tan atractivo el modelo alexiano (López.2003), que entiende al derecho como el conjunto de reglas, principios y procedimientos, buscando asegurar la racionalidad, al proponer cuatro postulados procedimentales prácticos: 1) claridad lingüística conceptual; 2) información empírica; 3) universalidad de la decisión; 4) desperjuiciamiento.

\footnotetext{
${ }^{8}$ Teoría desarrollada y analizada ampliamente por Robert Alexy profesor de Filosofía del Derecho y Derecho Público en la Universidad de Kiel (Alemania) toma de la teoría del discurso de Habermas el modelo de argumentación jurídico. Considerando a la argumentación jurídica como un caso especial del discurso práctico general.
} 


\section{Derecho y Ciencias Sociales, Abril 2009, Nº1. Pgs.194-215. ISSN 1852-2971}

Instituto de Cultura Jurídica y Maestría en Sociología Jurídica. FCJyS, UNLP

Los jueces siempre han utilizado diferentes métodos para interpretar y aplicar las normas generales. Según las circunstancias históricas ciertos métodos prevalecen sobre otros. El hecho es que tanto jueces como científicos del Derecho, encuentran en la ley elementos esenciales que requieren el uso de técnicas específicas para aprovecharlos, de manera que sirva para la creación y aplicación del derecho.

Un buen juez - dice Cueto Rúa (2000, p 228) - es un buen lector-escritor. Es que en la resolución de un conflicto requiere de cierto dominio de la sintaxis y la semántica que nos permitan conocer la estructura del idioma. Porque las palabras son signos que nos permiten expresar conceptos y estos son construcciones ideales que podemos expresar.

La palabra jurídica (esto es lo dicho tanto por las normas, como por los jueces o demás operadores jurídicos), está referida a acciones humanas. Sin embargo, ni las normas ni las sentencias tienen sus propias reglas, ya que dependen de las reglas de la gramática, mientras que las conductas son explicadas por motivaciones psicológicas o médicas, por lo que reconocemos la imposibilidad de reducir la norma a las conductas o viceversa, motivo por el cual nos interesa presentar una visión de integración.

El factor determinante, que define el razonamiento judicial, lo encontraremos en el valor que se pone en juego en el caso concreto y en la selección de aquel valor merecedor de reconocimiento judicial. Por ello podemos afirmar que la teoría de los métodos interpretativos, están esencialmente entrelazadas con la teoría de los valores jurídicos.

\section{La importancia de la argumentación}

Cuando una solución se presenta como la única admisible por razones de buen sentido, de equidad o de interés general, por su peso argumental tiende a imponerse en el campo jurídico, aunque se necesite recurrir a una argumentación especial, para mostrar su conformidad con las normas legales. La solución se vuelve aceptable solo, cuando ella va acompañada de cierto consenso social y de una argumentación jurídica suficientemente sólida.

La preocupación de Perelman (1974), al enfocar sus estudios hacia la lógica jurídica, se refieren a la búsqueda de la solución justa; tarea que de por si distingue la magistratura, como actividad, y que solo es posible lograr, cuando la decisión razonable, 
se encuentra basada en criterios de aceptación social. En principio no puede existir contradicción entre lo justo y lo razonable.

El derecho es visto como un instrumento flexible y capaz de adaptarse a valores que el juez considera como prioritarios, para la sociedad, ya que su papel es conciliar estos valores con las leyes y las instituciones establecidas, de manera tal que con ello se ponga de manifiesto no sólo la legalidad, sino también el carácter razonable de sus decisiones.

Cuando se subraya la primacía de la ley, no solo se entiende que el juez solo está sometido a ella, sino que también se reconoce al poder legislativo la facultad única como creador de toda norma jurídica. Si mantenemos esta posición y no distinguimos, entre normas generales y particulares, como diferenciara Kelsen, podremos observar que desde esta postura, el poder de interpretación del juez depende de la invocación a la voluntad del legislador, de la que nos hablara la escuela de la exégesis, como si esa voluntad continuara siendo la misma a pesar de la evolución técnica, moral o política que se hubiera producido en el transcurso del tiempo. El juez según Perelman, no debe buscar la voluntad histórica del legislador que votó la ley, recurriendo a trabajos parlamentarios o los debatas que precedieron su votación; tiene que ir en búsqueda del legislador actual, para entender la norma según las circunstancias actuales que motivan su aplicación. Esto nos lleva a considerar que la acción de juzgar puede estar motivada en la idea de equidad; con la condición de que se pueda encontrar un fundamento jurídico satisfactorio. Pero para que lleguemos a una decisión que merece ser llamada equitativa ella debe responder a ambas circunstancias: ser oportuna y socialmente útil.

En un pleito judicial cada una de las partes expone sus motivos, fundados en la jurisprudencia más benigna o en planteos doctrinarios, con la intención de argumentar favoreciendo su particular posición, con la intención de motivar en tal sentido la decisión del juez, logrando su convencimiento ${ }^{9}$. La solución jurisdiccional es producto de un proceso de análisis, en el que cada paso debe asumir el anterior y mejorarlo. Desde una perspectiva fenomenológica propuesta por Anduret (2002), se identifican cuatro regiones sentenciales, las que presentan una totalidad discursiva de entidad ontológica.

\footnotetext{
${ }^{9}$ Perelman señala la importancia de los tribunales de casación en la determinación de criterios jurisprudenciales que manifiestan el stare decis y en tal sentido establecen un criterio de razonamiento; para la que requieren de una lógica argumentativa. (en Lógica jurídica y nueva retórica. pág, 219 y 233).
} 


\section{Derecho y Ciencias Sociales, Abril 2009, Nº1. Pgs.194-215. ISSN 1852-2971}

Instituto de Cultura Jurídica y Maestría en Sociología Jurídica. FCJyS, UNLP

Tales regiones a considerar son: 1) hechos / derechos; 2) inserción sentencial; 3) argumentación y 4) justificación / motivación.

Respecto de los hechos podemos decir, que en todo expediente judicial, encontramos una referencia a situación fácticas constituidas por la situación litigiosa y por la producción de aquella prueba que han realizado las partes en el proceso, que permiten demostrar los hechos y sirven para dar un fundamente al derecho del que se pretende ser objeto. Los hechos que van a tener entidad o valor para la sentencia serán sólo, aquellos que recibirán una inserción sentencial, al ser estimados como altamente importantes para fundamentar una resolución.

Este primer y segundo paso, pueden ser incluidos dentro de lo que Andruet llama justificación interna, con relación al acto de sentenciar, en la medida que las pruebas, sobre los hechos y los derechos alegados, conforman un núcleo inescindible, que le permite al juzgador construir convicciones. Mientras que la justificación externa, está dirigida al auditorio, que podemos definir como aquellos a quienes el orador quiere influir para lograr su convencimiento, con la exposición de motivos.

Si bien puede perderse de vista el perfil antropológico del auditorio para pasar a ser un objeto teórico, en la medida que no solo teorizamos sobre él, sino que además se transforma en aquello a lo que se dirigen nuestros actos de habla presentes o futuros. El auditorio juega un papel importante en el discurso en general, en la medida, que este debe ser adaptado según aspectos cualitativos y cuantitativos, ya que entran a jugar circunstancias que se pueden hacer valer en la misma argumentación. Específicamente el auditorio forense ${ }^{10}$ posee características particulares, porque se lo puede definir como universal en la medida que reconocemos la atemporalidad de las sentencias y el juego argumental que propone; de tal forma que se deben ponderar las distintas líneas argumentales en función de la posibilidad de éxito o fracaso y de crítica o aceptación, que el orador tiene que imaginar al momento de la creación discursiva.

Dicha justificación externa está compuesta por la tercera región que denominamos argumentación que se estructura como una razonamiento silogístico de carácter práctico prudencial, que toma para su construcción modelos o paradigmas de conductas, socialmente valiosas. Claro que esta región puede ser pasible de vicios como la equivocación, la mala disposición argumental o la incoherencia, que provocan la

\footnotetext{
${ }^{10}$ Podemos mencionar distintos tipos de auditorios a saber el singular (compuesto por una persono) o solipsista (cuando se argumenta en contra de quien los expusiera). Pettoruti, Scatolini Elementos de introducción al derecho, pág, 164.
} 
incomunicación, por imposibilidad de decodificar el discurso, suscitando el rechazo por parte del auditorio.

La cuarta región la denominamos: motivación, que resulta ónticamente incognocible (Andruet.2002), porque tiene que ver con lo subjetivo; sin embargo, el discurso nos permite descubrir sus contornos.

Los motivos se basan en tres elementos diferentes: ideológico (política o religiosa), axiológico (criterios valorativos, valores-antivalores), ambas pertenecientes en los objetos culturales; mientras que el tercer elemento es llamado idiosincrático y se refiere a concepciones, pasiones, sensaciones, deseos, ansiedades, temores y triunfos; que son parte de la opción que una persona toma y son característicos del ser humano.

Cada una de estas regiones fundamentan el acto voluntario de toma de decisiones en los que se puede privilegiar distintos aspectos como: 1. Adhesión voluntaria a principios generales de conducta. 2. Obediencia a determinadas prescripciones. 3. Reclamos exteriores o necesidades sociales.

En definitiva, si alguien desconociera el motivo que guía su discurso o siquiera le importara, nos encontraríamos ante una situación de ignorancia operacional, eminentemente peligrosa y totalmente injustificable si la consideramos, en relación al discurso jurídico.

\section{Proceso hermenéutico jurídico}

La interpretación es una actividad de suma importancia en el campo jurídico. Generalmente se la asocia solamente a la intelección de la ley, pero esto es solo una parte que tiene dentro del mundo jurídico.

El proceso judicial esta construido como un modo de alcanzar la comprensión, no solo de los intereses de las distintas partes, sino también la búsqueda de la integración entre conducta y la norma, en la medida de encontrar una adaptación al tipo penal.

La sentencia, es la justificación de una decisión del órgano jurisdiccional, que se nos presenta como una solución al conformarse como la síntesis que enlaza ambos aspectos dialécticos - norma-conducta - por medio de la interpretación hermenéuticojurídica. La argumentación juega un papel destacado en esta instancia, porque actúa como la base del razonamiento utilizado en la toma de decisión por el magistrado. 


\section{Derecho y Ciencias Sociales, Abril 2009, Nº1. Pgs.194-215. ISSN 1852-2971}

Instituto de Cultura Jurídica y Maestría en Sociología Jurídica. FCJyS, UNLP

Martín Heidegger, ha profundizado el estudio del proceso hermenéutico, como así también, lo que conlleva esta actividad. El término "hermenéutico", no lo podremos definir de modo semejante al concepto "comprender", pero no obstante lo supone o es parte del proceso. Por eso, el desarrollo del comprender podemos llamarlo interpretación; porque la actividad del comprender, importa apropiarnos de lo comprendido, comprendiendo. Haciéndosenos tan claro y patente que ya se nos hace nuestro, conformando un saber "propio" (lo que yo se). Este comprender doble comprender lo comprendido - podemos llamarlo interpretación, en la que no se comprende otra cosa distinta, sino que se vuelve a la misma cosa. En tal sentido Heidegger afirma que: "la interpretación se funda existenciariemente, en lugar de surgir ésta de ella. La interpretación no es el tomar conocimiento de lo comprendido, sino el desarrollo de las posibilidades proyectadas en el comprender" (Heidegger.1974, p 166).

Toda desarrollo de actividad humana, se base en los actitudes previamente adquiridas por el sujeto, las que en algunos casos tienen un carácter limitativo; mientras que en otros casos son capacidades que permiten alcanzar una plenitud de cierto estado evolutivo.

La actividad interpretativa - como actividad que es - se funda en un "concebir previo". Porque se lleva a cabo desde "supuestos". Por ello se ha dicho que en el proceso interpretativo, el intérprete está ya de antemano, previamente, comprometido, puesto que sus conocimientos, creencias, perjuicios, intereses, etc. condicionan su interpretación (Petzold Pernia.1997).

El intérprete, como protagonista, es inescindible de su actividad dado que se encuentra totalmente involucrado al poner en juego sus conocimientos, creencias, prejuicios, intereses, etc., que condicionan de alguna manera la interpretación.

La posibilidad de los entes, responde a las distintas formas de ser comprendidos, por lo que reconocemos un "sentido" en cada texto, adquiriendo de este modo un "estado comprensible"; en el que la armazón formal se hace inherente a la interpretación. Así la posibilidad de interpretar depende de la comprensión y de descubrir el sentido contextual, ambos nos suministrarán una referencia estructural.

Para reconocer todas las posibilidades hermenéuticas se hace indispensable conocer su autor y el contexto espacio-temporal en el que el texto fue elaborado. No pocas comunicaciones científica-jurídicas se interesan por ampliar el marco referencial y mostrar una perspectiva histórica, filosófica, social y política. Afirmar la necesidad de 


\section{Derecho y Ciencias Sociales, Abril 2009, №1. Pgs.194-215. ISSN 1852-2971}

Instituto de Cultura Jurídica y Maestría en Sociología Jurídica. FCJyS, UNLP

un "circulo de comprensión", en el que lo singular y el todo se remiten uno al otro, concretando una aprehensión para pasar de lo general a lo individual y viceversa. Porque en la hermenéutica existencial de Heidegger nos lleva a una comprensión del mundo en el que la existencia, se comprende en él y a su vez la existencia permite comprender lo mundano (Pettoruti. 2007).

En general podemos decir que el legislador redacta los textos que luego promulgará, que contienen las distintas reglas de acción, que guían el obrar de los ciudadanos. Claro que todos obramos, pues hay decisiones que tomar y actos que cumplir, según determinados criterios. Pero estas reglas a las que nos referimos tienen por sí un interés capital; ellas nos dicen lo que se juzga como deseable.

El juez se muestra como el intérprete de la voluntad de la ley, es el intermediario ente el texto y la situación concreta. En este aspecto podemos comprender en profundidad la importancia fundamental de la filosofía del derecho, porque la actividad interpretativa posee un substrato filosófico, porque implica tomar partido por una concepción del derecho.

Así el resultado de la interpretación judicial alberga un saber no sólo jusfilosófico de carácter científico y jurídico sino también de tipo prudencial y retórico. La conclusión a la que llegará es fruto de un silogismo prudencial, en tanto que la decisión jurisdiccional utiliza una técnica retórica argumentativa, para lograr una justificación objetiva, en la medida en que muestra cierta razonabilidad que permite persuadir al auditorio (Tinat.1997).

La justificación de una sentencia depende de su conformidad con lo justo, esto se prueba, si la argumentación-retórica utilizada es justificable, porque sus premisas persuasivas o disuasivas, fundan una estructura discursiva sustentable tornando legítima la decisión judicial.

Los distintos Códigos Procesales en materia Penal nos hablan de la "convicción sincera" o de la "libre convicción razonada", a la que se llega por medio de esta técnica dialéctica argumentativa. Para lo cual el juez necesita alcanzar la convicción de la existencia histórica de los hechos a juzgar, momento procesal en el que las partes litigantes no se encuentran ajenas, intentando justificar sus propias afirmaciones; si bien el juzgador se encuentra limitado por un lado a las pruebas efectivamente producidas y por otro, la restricción al someterse al sistema de prueba legal o tasada. La apreciación 
del juez permite generar una convicción que se manifestará en al sentencia en la que se volcará el análisis de las probanzas, que motivan de modo sustancial el fallo judicial.

El razonamiento judicial se da en un proceso y con motivo de un proceso. En el que se presentan dos partes, que dirigidas por un juez, discutirán sus posturas según determinadas reglas establecidas por las normas adjetivas.

El propio vocablo proceso nos habla de distintos momentos o etapas que permitirán alcanzar el fin. Esta sucesión de diferentes tiempos procesales está marcada por la contradicción y el diálogo.

La sentencia judicial debe estar sometida a un control de logicidad (Ghirardi.2003), lo que implica determinar si la argumentación jurídica está guiada por principios lógicos como el de no contradicción (que posee jerarquía constitucional) porque de ellos depende la validez de los pronunciamientos.

Los tribunales de casación tienen la misión de corregir los errores in cogitando cuando las razones que fundamentan la sentencia devienen en una sentencia arbitraria.

Siempre existen diversas alternativas al tomarse una decisión jurisdiccional sin embargo, la opción elegida debe ser fundamentada en razones, que no tengan contradicción alguna. En tal sentido Ghirardi(2003) distingue: un aspecto formal, que hace a la corrección proposicional utilizada en la fundamentación (corrección lógica). Y un aspecto sustancial, que se relaciona con el contenido de la propia decisión (corrección jurídica).

Esta diversidad de elección se fundamenta, en que el ser del hombre conlleva un poder ser - según afirma Tinant (1997) - mientras exista ser siempre hay una posibilidad de otra cosa, porque existir implica para el hombre constituirse como un ser posible, en tanto que su obrar humano fluye en libertad. Reflejándose tanto en la creación como en la aplicación del derecho.

Por lo expuesto podemos decir que no es posible hablar de una única interpretación "verdadera", elegida entre varias otras, sobre un texto jurídico porque siempre nos enfrentaremos a la variada posibilidad hermenéutica que dicho texto ofrece.

No obstante, descubrimos en el Derecho una ratio juris, constituida por la unidad sistemática que contiene; fundada en una jerarquización de valores. El descubrimiento de estos valores nos permite alcanzar cierta coherencia intrasistemática o la ratio legis, de las normas jurídicas en general que nos permita establecer razonablemente su sentido y finalidad. 
El intérprete debe tener en cuenta las necesidades colectivas presentes y las valoraciones sociales vigentes, a fin de lograr, no una interpretación supuestamente "verdadera" de las normas, sino la interpretación más razonable en cada ocasión concreta, puesto que lo irrazonable no es Derecho.

\section{Necesidad de la argumentación}

Como sostiene Genaro Carrió (2003), la labor de los abogados es ciertamente técnica, pues consiste en usar ciertos medios para alcanzar un resultado a partir de una situación inicial dada. Mientras que la de los jueces consiste en utilizar normas generales para justificar decisiones particulares y concretas.

Para mayor abundamiento podríamos decir que tanto los jueces como los abogados utilizan reglas técnicas explicitadas por el Derecho Procesal. Así los distintos operadores jurídicos recurren al derecho de fondo con la intención de argumentar jurídicamente, para instar la acción o en función de un requerimiento de la parte, como es propio en la actividad de los abogados, y que los jueces también deben realizar al momento de fundamentar sus decisiones.

Podemos reconocer que todo acto humano, sin excepción alguna, es susceptible de ser percibido desde la perspectiva del juez, del abogado o del jurista y valorado y juzgado como acto jurídicamente significativo.

De todo acto humano exterior, perceptible por los sentidos, se puede predicar que este constituye:

a)- el ejercicio de una potestad. b)- el padecimiento de un deber jurídico. c)- la violación de un deber jurídico. d)- el padecimiento de una sanción aplicada por un órgano jurisdiccional competente.

Lo propio de la tarea del juez y del abogado en el fondo es la misma desde distintos prismas de la realidad, la que se encuentra caracterizada, por predicar la significación jurídica como potestad o prestación, o como entuerto o sanción. Para lo cual necesitan valorar desde aquellos valores vigentes en la comunidad, como así también, desde los valores vigentes en las normas jurídicas.

La experiencia jurídica comienza, para los jueces y abogados desde el contacto con las partes; no así para estas últimas, que se inicia en una etapa previa (ejemplo: desde la firma del contrato). Desde el conocimiento fáctico de la realidad, los jueces y abogados otorgan al hecho o acción significación jurídica, al valorar la conducta. 
Sin embargo, esto no es todo; falta que el juez y el abogado le otorguen una significación normativa, a la situación descripta por las partes; lo que implica ahora, una selección normativa susceptible de ser aplicada al caso, para el que se deberá tener en cuenta los aspectos relevantes del hecho jurídico.

\section{El control de logicidad en el razonamiento judicial}

Nos interesa en este caso estudiar el razonamiento judicial poniendo el acento en el aspecto exclusivamente formal, para ello será necesario examinar su significación lógica. Sabemos que este tipo de razonamiento, opera teniendo en cuenta reglas de contenido jurídico, frente al hecho empírico que se nos presenta. Estas reglas, intentan dar una solución lógicamente correcta, que nos permita justificar la conclusión a la que arribamos. Por este motivo, necesitamos indispensablemente interpretar las reglas jurídicas. Esta finalidad hace que las reglas del razonamiento sean múltiples y diferentes, atento la necesidad de tomar la mayor cantidad de elementos lógicos que permitan la mejor argumentación posible.

Según MacCormick, el razonamiento jurídico es una rama del razonamiento práctico y asume la forma de una técnica de aplicación de las reglas jurídicas, caracterizándose por ser un razonamiento primordialmente deductivo. Es por este motivo que la forma lógica que se da a este razonamiento, tiene relación con el modo en que se lo justifique. Así el juez al redactar su sentencia, tiene la obligación de fundamentarla racionalmente, por ello recurre a aquellas proposiciones, juicios y razonamientos que revelan un itinerario lógico, que nos muevan hacia una resolución, que genere convicción.

La lógica tiene para la filosofía una función netamente técnica, en cuanto le permite establecer las reglas del razonamiento correcto; preocupándose solo por la forma en que se instrumenta la reflexión racional, más no por el contenido de la misma. Por tal motivo podemos diferenciar entre lo verdadero y lo correcto, porque no son una misma cosa; ya que un razonamiento puede ser elaborado correctamente y llegar a una conclusión falsa; mientras que si partimos de premisas verdaderas y razonamos correctamente, tendremos la garantía de permanecer en la verdad. El razonamiento correcto tiene pretensiones de "validez" en la medida que nos permite alcanzar lo verosímil, en el sentido que nos aproxima a lo verdadero pero carece de la fuerza de la evidencia para que sea reconocida como tal. 
La importancia que le damos a un razonamiento correcto y la aplicación que tiene en el campo jurídico, la palpamos en la intervención de los distintos actores jurídicos en el proceso judicial, por el modo en que se valen del razonamiento para estructurar y dar sentido a su posición, como también así, el propio juez que en su sentencia hará uso de este recurso debiendo fundamentar su resolución. Esto nos lleva a entender, que los tribunales de alzada deben realizar un control de logicidad.

$\mathrm{Si}$ nos detenemos a pensar la estructura del silogismo judicial podemos reconocer que está compuesto por una premisa mayor con forma de proposición universal, que indica la realización de una acción (lo que se debe), contraponiendo una premisa menor, establecida por una proposición que contiene un sujeto individual, que ha realizado la acción, que es descripta por la norma - en su carácter de premisa universal - cuya conclusión enlaza, el predicado de la mayor con el sujeto de la premisa menor.

El silogismo judicial posee como característica central el referirse a una acción (robo a mano armada) relacionada a un hecho a ejecutar (pena de prisión), como consecuencia de un acto realizado (robo). La proposición jurídica, al hacer mención del "deber" nos indica que estamos en el universo judicial.

En el silogismo lógico formal aristotélico se convierte en fundamental, produciendo el paso de lo universal a lo particular siempre que se establezca entre ellos una relación de género a especie. Los dos problemas del juez son: a) determinar la norma aplicable - premisa mayor - constituido por los principios y las prescripciones normativas que establecen el género que actúa como categoría de los hechos

Mientras que el otro será: b) establecer los hechos, conductas y acciones de relevancia jurídica.

Según el pensamiento clásico podemos distinguir entre el razonamiento teórico o especulativo que se ocupa de "lo que es", mientras que el saber práctico tiene por objeto "lo que debe ser". Insertado dentro de la esfera de la filosofía práctica, es un tipo de reflexión que apunta a lo que debe ser realizado en la acción humana, según requerimientos de razonabilidad. Establece argumentos, construidos con el fin de mostrar qué valores debemos perseguir, en función de establecer razones para la acción, como guías de conducta, adquiriendo un profundo sentido axiológico (Vigo.2004).

Podemos reconocer en el razonamiento jurídico una rama específica del razonamiento práctico, que es compartida por la Ciencia Jurídica, como parte de la 


\section{Derecho y Ciencias Sociales, Abril 2009, №1. Pgs.194-215. ISSN 1852-2971}

Instituto de Cultura Jurídica y Maestría en Sociología Jurídica. FCJyS, UNLP

reflexión sobre la praxis humana. $\mathrm{Si}$ entendemos al Derecho como conducta en interferencia intersubjetiva y a la norma como una modalidad de la acción ${ }^{11}$.

\section{Conclusión}

A modo de conclusión podemos remarcar que explorar la razón jurídica implica traspasar el campo de la lógica tradicional, en busca de la razón vital e histórica o mejor dicho establecer una lógica de la acción, ya que la vida humana es el reino de la acción y la libertad.

En este sentido, tanto la lógica formal como la lógica dialéctica, deben integrarse y complementarse frente a las necesidades del discurso jurídico, que pretende ser razonable y alcanzar cierto grado de corrección.

Así la elaboración de una conclusión o solución, implica la necesidad de reconocer, la validez de ciertas reglas lógicas, que serán necesarias a la hora de producir el razonamiento. Este es el motivo por el cual el silogismo dialéctico, se funda en la verosimilitud, ya que necesita de buenas razones que justifiquen las decisiones.

Debiéndose destacar la doble función objetivante de la norma como parte del conocimiento jurídico, tanto lógico como axiológico. Que nos obliga a observar el lenguaje normativo, cuyo significado racionalmente inteligible nos permite categorizar las acciones humanas.

De este modo la sentencia, puede ser vista como, la justificación de una decisión del órgano jurisdiccional, que se nos presenta como una solución que se constituye como síntesis del proceso dialéctico que enlaza ambos aspectos - norma-conducta - por medio de la interpretación hermenéutico-jurídica. En el cual la argumentación juega un papel destacado en esta instancia, porque actúa como la base del razonamiento que será utilizado en la toma de decisión, por parte del magistrado. Este movimiento de síntesis, comienza con una tarea de clarificación del lenguaje normativo y finaliza con la búsqueda de la corrección del sentido jurídico en la decisión judicial.

\section{$\underline{\text { Bibliografía }}$}

\footnotetext{
${ }^{11}$ El propio Olsen Ghirardi en distintos trabajos afirma que el Derecho es una modalidad de la conducta; nosotros preferimos reconocer que solo las normas cumplen una función modal con características lógica que le son propias mientras que la conducta manifiesta un aspecto axiológico, siendo su relación dialéctica el objeto propio de la Ciencia Jurídica
} 
Aarnio Aulius. (2005) “Algunas observaciones sobre la justificación jurídica”. Comp. Zuleta Puceiro E. Interpretación de la ley. La ley. Buenos Aires.

Andruet Armando. (2001) Teoría general de la argumentación forense. Alveroni. Córdoba.

Andruet Armando. (2002) "Aportes para una teoría fenomenológica de la decisión jurisprudencial". Actitudes y planos en el razonamiento forense. Córdoba. Academia Nacional de Derecho y Cs. Sociales de Córdoba.

Andruet Armando. S. (2000) Teoría general de la argumentación forense. Alveroni. Córdoba.

Carrió Genaro. (2003) Cómo estudiar y cómo argumentar un caso. 2da. Edición. Lexis Nexis. Buenos Aires.

Cossio Carlos. (1940) El substrato filosófico de los métodos interpretativos. Universidad del Litoral. Santa Fe.

Cueto Rúa Julio. (2000) Una visión realista del Derecho. Abeledo Perrot. Buenos Aires.

Cueto Rúa Julio. C. (2000) Derecho y realidad. Abeledo Perrot. Buenos Aires.

Diez Picazo L. (1994) Experiencias jurídicas y teoría del derecho. Ariel. Buenos Aires. Ghirardi Olsen. (1997) El razonamiento Judicial y el control de logicidad . XVIII Congreso Internacional de Filosofía del Derecho. Buenos Aires.

Ghirardi Olsen. (2003) Introducción al razonamiento forense. Duken. Buenos Aires .

Ghirardi Olsen. A. (1987) Logica del proceso judicial. Córdoba. Lerner. Córdoba.

Ghirardi Olsen. A. (2006) Cuestiones jusfilosóficas. www.acader.unc.edu.ar. Academia Nacional de Derecho y Ciencias Sociales de Córdoba.

Heidegger Martín. (1974) Ser y tiempo. 5ta. Ed. Fondo de cultura económica. México. Kelsen Hans. (1992) Teoría Pura del Derecho. 29na. Ed. Eudeba. Buenos Aires.

López María. T. (2003) La interpretación jurídica. Tercer encuentro de profesores de Introducción al Derecho. Santa Rosa. Prov. de la Pampa.

Machado Neto A. L. (1974) Fundamentación egológica de la teoría general del derecho. Eudeba. Buenos Aires . 


\section{Derecho y Ciencias Sociales, Abril 2009, Nº1. Pgs.194-215. ISSN 1852-2971 \\ Instituto de Cultura Jurídica y Maestría en Sociología Jurídica. FCJyS, UNLP}

Maritain Jaques. (1980) El orden de los conceptos. Lógica. Club de lectores. Buenos Aires.

Millan Puelles A. (1981) Fundamentos de Filosofía. Pialp. 11ma. Ed. Madrid.

Perelman Chain. (1979) Lógica jurídica y la nueva retórica. Ed. Cívitas. Madrid.

Pettoruti C. Scatolini J. (2005) Elementos de introducción al derecho. La ley. Buenos Aires.

Pettoruti Carlos. E. (2004) La validez del derecho. La ley. Buenos Aires.

Pettoruti Carlos. E. (2007) "Modernismo filosófico, reforma universitaria y enseñanza del derecho en la UNLP”. Revista Anales. Año 3, №36. La Plata.

Petzold Pernia H. (1997) Breves consideraciones sobre la naturaleza del proceso hermenéutico jurídico. XVII Congreso Internacional de Filosofía del Derecho. Buenos Aires .

Recaséns Siches L. (1956) Nueva filosofía de la interpretación del Derecho. Fondo de Cultura Económica. México.

Recaséns Siches L. (1971) Experiencia jurídica, naturaleza de las cosas y lógica razonable. Fondo de Cultura Económica. México.

Ricour Paul (2001) Del texto a la acción. Fondo de cultura económica. Buenos Aires Buenos Aires.

Smith J. C. (1990) “La interpretación jurídica una movimiento de síntesis”. El Derecho. T 138, UCA. Buenos Aires.

Stein Edith. (2003) La pasión por la verdad. 2da ed.Bonum. Buenos Aires.

Tinat Eduardo. L. (1997) Acerca de la justificación de la decisión judicial. Comunicación. XVII Congreso Internacional de Filosofía del Derecho. Buenos Aires. .

Vigo Rodolfo. (2004) "Razonamiento justificatorio judicial". Jurisprudencia Argentina. Nro. 13. Buenos Aires.

Walter Robert. (2001) La doctrina del derecho de Hans Kelsen. Universidad Externado de Colombia. Colombia. 